\title{
Description of Prescribing Practices of Intrapleural Tissue Plasminogen Activator and Intrapleural DNase Administration at a Tertiary Academic Medical Center
}

\author{
Heather Torbic*, Gaspar Hacobian, Nahal Beik \\ Department of Pharmacy, Brigham and Women's Hospital, Boston, USA \\ Email: ${ }^{*}$ htorbic@partners.org
}

Received 29 June 2014; revised 28 July 2014; accepted 13 August 2014

Copyright (C) 2014 by authors and Scientific Research Publishing Inc.

This work is licensed under the Creative Commons Attribution International License (CC BY). http://creativecommons.org/licenses/by/4.0/

\section{(c) (i) Open Access}

\begin{abstract}
Objectives: To describe the prescribing practices, preparation and administration techniques of intrapleural (IP) tissue plasminogen activator (t-PA) and IP DNase in patients at a tertiary academic medical center. Methods: Adult patients receiving IP t-PA and IP DNase between January 1-December 31, 2012 were retrospectively evaluated. Patients were included if they received IP t-PA and/or IP DNase for a pleural infection and were excluded if they received IP t-PA or IP DNase for chest tube clearance. Results: A total of 197 doses of IP t-PA and IP DNase received amongst 30 patients were included. The mean age of the patients included was 62 years old with $50 \%$ of the patients being female. Of the 30 patients included, 18 patients $(60 \%)$ received both IP t-PA and IP DNase and 12 patients (40\%) received only IP t-PA. The median dose of IP t-PA received was $4 \mathrm{mg}$ (IQR 2-10) and the median dose of IP DNase received was $5 \mathrm{mg}$ (IQR 5-5). Systemic antibiotics were administered to $77 \%$ of patients prior to IP t-PA or IP DNase administration. Improved pleural effusion drainage was reported in $70 \%$ of patients. Increased pain in the chest cavity during administration of IP t-PA or IP DNase was reported in 7\% of patients. Conclusion: The majority of patients at our institution received concomitant IP t-PA and IP DNase after systemic therapy for treatment of pleural infections had been attempted. Administration of IP t-PA and IP DNase demonstrated improved drainage of pleural infections with minimal harm to patients.
\end{abstract}

\section{Keywords}

Intrapleural, Tissue Plasminogen Activator, DNase, Pleural Effusion

\footnotetext{
${ }^{*}$ Corresponding author.
} 


\section{Introduction}

In critically ill patients, pleural effusions are common and affect more than 65,000 patients each year in the United States and the United Kingdom, with the incidence continuing to rise [1]-[3]. Between $10 \%$ to $20 \%$ of patients with pleural infections die and one-third of patients with pleural infections require surgical drainage due to failure of drainage of infected fluid through a chest tube and administration of systemic antibiotics [2]-[4]. The median extended duration of hospital stay for patients who fail standard therapy and go on to require surgical drainage of their pleural effusion is 12 - 15 days, which ultimately results in greater healthcare costs [2] [4] [5].

It has been suggested that using fibrinolytic drugs in the intrapleural (IP) space can improve outcomes for patients with pleural effusions by improving chest tube drainage and thus reducing surgical referral [6] [7], however the MIST1 trial and a subsequent meta-analysis showed no benefit with IP streptokinase [4] [8]. Rahman and colleagues demonstrated that the addition of IP recombinant human DNase to a more direct acting IP fibrinolytic like tissue plasminogen activator (t-PA) improved chest tube drainage of pleural effusions and decreased the need for surgical intervention and extended hospital stay, however larger trials are needed to replicate the results [9].

The use of IP t-PA and IP DNase may be indicated after chest tube drainage and systemic antimicrobial therapy has been insufficient to manage pleural effusions. However, limited data exist describing the prescribing practices of IP t-PA and IP DNase for pleural infections, including the procedures for preparing and administering these products. The objective of this study is to describe the practice of IP t-PA and IP DNase administration in patients with pleural infections at a tertiary academic medical center.

\section{Methods}

This was a single-center, retrospective, descriptive analysis of clinical practice of adult patients admitted to our 793-bed academic medical center who received IP t-PA and/or IP DNase. The institutional review board at Brigham and Women's Hospital reviewed and approved the study protocol prior to data collection.

An internal database was used to identify all patients who were ordered for t-PA or DNase between January 1, 2012 and December 31, 2012. To be included in the analysis, patients had to be $\geq 18$ years of age and received at least one dose of IP t-PA and/or IP DNase for a pleural infection. Patients were excluded if they received t-PA and/or DNase via a route other than IP or received IP t-PA and/or IP DNase for chest tube clearance.

Investigators collected data retrospectively, and demographic data collected included age, gender, ethnicity, comorbidities, indication for IP t-PA and/or IP DNase, admitting service, intensive care unit (ICU) admission, and hospital length of stay. Outcomes assessed included dose administered, dose preparation and administration techniques, cumulative doses, systemic antibiotic therapy, and any documented efficacy and safety endpoints in patient charts. Efficacy endpoints were defined as documentation of increased chest tube drainage after IP t-PA and/or IP DNase administration. We assessed safety endpoints by reviewing notes in the patient chart suggesting there was an adverse event directly related to IP t-PA and/or IP DNase administration (e.g. pain with administration or evidence of irritation to the chest cavity).

\section{Results}

A total of 6075 doses of t-PA and DNase were evaluated for inclusion in this analysis. The number of doses excluded was 5878 because t-PA and DNase were not administered via the IP route or were used for chest tube clearance. Therefore, a total of 197 doses were included in the analysis, with 110 IP t-PA doses and 87 IP DNase doses divided amongst 30 patients. Baseline characteristics can be found in Table 1.

The primary indication for IP t-PA and IP DNase therapy was a complicated pleural effusion (83.3\%) followed by empyema (16.7\%). Twenty-three patients received systemic antibiotics prior to IP therapy. The majority of patients received both IP t-PA and IP DNase therapy (60\%), while only $40 \%$ of patients received IP t-PA alone and no patients received only IP DNase therapy. The median number of IP t-PA doses received per patient was 3 (IQR 1-5) and IP DNase doses was 3 (IQR 2-6). The median dose of IP t-PA received by patients was 4 $\mathrm{mg}$ (IQR 2-10) and the only dose of IP DNase received by patients was $5 \mathrm{mg}$.

The majority of doses were prepared by the pharmacy department in the sterile products room (IP t-PA, 82.7\% and IP DNase 97.7\%). Doses that were not prepared by the pharmacy department were prepared on the floor by a nurse or physician prior to administration. Most doses of IP t-PA were prepared in $30 \mathrm{~mL}$ of $0.9 \%$ 
Table 1. Baseline characteristics.

\begin{tabular}{lc}
\hline Variable & Patients \\
\cline { 2 - 2 } Age, years & $\mathrm{N}=30$ \\
Gender: male $^{* * *}$ & $63 \pm 16$ \\
Ethnicity $_{\text {White }}^{* *}$ & $15(50.0)$ \\
Hispanic $^{* *}$ & $24(80.0)$ \\
African American $^{* *}$ & $5(16.7)$ \\
Comorbidities $^{* *}$ & $1(3.3)$ \\
Hypertension $^{* *}$ & \\
CAD $^{* *}$ & $11(36.6)$ \\
PAH $^{* *}$ & $5(16.7)$ \\
CHF $^{* *}$ & $2(6.7)$ \\
COPD $^{* *}$ & $6(20.0)$ \\
Asthma* $^{* *}$ & $2(6.7)$ \\
Active malignancy $^{* *}$ & $3(10.0)$ \\
ICU admission $^{* *}$ & $18(60.0)$ \\
Hospital length of stay, days & $16(53.3)$ \\
Primary service & $16.8 \pm 10.8$ \\
Oncology $^{* *}$ & \\
Medicine $^{* *}$ & $11(36.7)$ \\
Thoracic surgery $^{* *}$ & $3(10.0)$ \\
General surgery $^{* *}$ & $9(30.0)$ \\
Cardiology $^{* *}$ & $4(13.3)$ \\
\hline & $3(10.0)$ \\
\hline
\end{tabular}

Data presented as * Mean \pm SD and ${ }^{* *} \mathrm{n}(\%)$; CAD: coronary artery disease, PAH: pulmonary arterial hypertension, CHF: congestive heart failure, COPD: chronic obstructive pulmonary disease, ICU: intensive care unit.

sodium chloride (89\%), while $9.9 \%$ of doses were prepared in $1000 \mathrm{~mL}$ of $0.9 \%$ sodium chloride and $1.1 \%$ of doses were prepared in $20 \mathrm{~mL}$ of $0.9 \%$ sodium chloride. The majority of IP DNase doses were prepared in 30 $\mathrm{mL}$ of sterile water $(92.9 \%)$, while $7.1 \%$ of doses were prepared in $30 \mathrm{~mL}$ of $0.9 \%$ sodium chloride.

In terms of efficacy, $70 \%$ of patients had improved chest tube drainage after administration of IP t-PA and IP DNase therapy, as defined as a greater than $20 \%$ improvement in chest tube output from baseline. No improvement was seen in $20 \%$ of patients and chest tube drainage was not reported in $10 \%$ of patients. All patients who had improved chest tube drainage received both IP t-PA and IP DNase. Two patients required surgical management of their empyema despite receiving systemic antibiotics and IP t-PA and IP DNase. In terms of adverse events, $93 \%$ of patients had no adverse events reported, while $7 \%$ of patients experienced increased pain in their chest cavity while IP t-PA and IP DNase were being administered.

Administration techniques were consistent amongst the patients in the analysis. Most patients first received IP t-PA, followed by IP DNase. The chest tube was then flushed with $100 \mathrm{~mL}$ of $0.9 \%$ sodium chloride. Next, the chest tube was clamped and the IP therapy was left to dwell for 60 minutes, after which the chest tube was unclamped and the chest tubes were allowed to drain. If the process was repeated, it was done every 12 - 24 hours.

\section{Discussion}

Pleural effusions and empyemas can lead to serious complications, including death, if left untreated [2] [4]. First line therapy includes systemic antibiotics and drainage via a chest tube [1]-[4]. Surgical management often occurs if first line therapy has failed [2]-[4]. The addition of IP fibrinolytic agents to standard therapy in an effort to improve drainage of pleural effusions or empyemas was proposed in the 1990's [6]. Smaller studies evaluating the benefit of IP fibrinolytic agents alone for management of pleural infections have produced favorable re- 
sults for this therapy [6] [7] [10]-[12], however, MIST1; a large, randomized, placebo-controlled trial was not able to replicate these favorable results [4]. The data evaluating IP DNase therapy alone for management of pleural infections is limited [13]. The addition of IP DNase therapy to IP fibrinolytic therapy was proposed with the assumption that this combination would have a synergistic effect. It was believed that pleural fluid when infected had an increased viscosity which was due to the presence of extracellular DNA and other bacterial components which IP DNase therapy would likely be able to break down to help improve chest tube drainage. A more recent, much larger study suggests that the combination of IP t-PA and IP DNase therapy may be more effective than either therapy alone for management of pleural infections [9].

Intrapleural t-PA and IP DNase therapy were studied concomitantly in a study by Rahman, et al. [9], evaluating 210 adult patients with pleural infection. Patients were randomized to receive IP t-PA plus IP DNase, IP t-PA plus placebo, IP DNase plus placebo, or placebo. The dosing for IP t-PA was $10 \mathrm{mg}$ twice daily for 3 days and the dosing for IP DNase was $5 \mathrm{mg}$ twice daily for 3 days. The investigators of the study found that only the combination of IP t-PA and IP DNase significantly improved the pleural opacity at day 7 compared to placebo and significantly reduced hospital length of stay with no significant difference in adverse events between the groups.

Our analysis is similar to the study by Rahman, et al. in that an improvement in pleural effusion occurred with the combination of IP t-PA and IP DNase therapy with minimal adverse events noted. Our analysis contributes to the literature by discussing the practice of IP t-PA and IP DNase preparation and administration at a tertiary academic medical center and describes the prescribing practices at this institution. Our analysis differs from the Rahman, et al. study since it is a small, retrospective analysis. Additionally, not all patients in our analysis received both IP t-PA and IP DNase therapy. In our analysis, no patients received IP DNase therapy alone, but $40 \%$ of patients only received IP t-PA. In the MIST1 study [4], fibrinolytic therapy alone was found to be ineffective for management of pleural effusions. In our analysis, three patients who only received IP t-PA, had an improvement in chest tube drainage. It is unclear if other interventions occurred in those patients affecting the results of the analysis. Finally, the median IP t-PA dose seen in our analysis is smaller than the IP t-PA dose used in the Rahman, et al. study. Further studies are needed to determine the ideal dose of IP t-PA.

There are several limitations to our analysis. First, this was a small, single center, observational, retrospective analysis. A major limitation is the fact that this analysis does not have a control group receiving standard pleural effusion management to compare IP t-PA and IP DNase therapy to. However, given the small sample size, this study would not be powered to detect a difference between groups.

Another limitation is the difference in indication for IP therapy amongst patients. Although most patients did receive IP therapy due to a pleural effusion, there were a small percentage of patients who received IP therapy for an empyema, which may affect the efficacy of therapy. Unfortunately, the sample size is too small to detect if this would make a difference in outcomes. Since only patients with pleural effusions or empyemas were studied, the results of this analysis cannot be applied to other patient populations.

A change in practice occurred at Brigham and Women's Hospital during the study period assessed that may have also affected the results of the analysis. During this time period, physician, nursing, and pharmacy leadership developed a drug administration guideline for both IP t-PA and IP DNase in an attempt to standardize therapy at our institution. In this guideline, an IP t-PA dose ranging from $2 \mathrm{mg}$ to $10 \mathrm{mg}$ was suggested and all doses were to be prepared in $30 \mathrm{~mL}$ of $0.9 \%$ sodium chloride. This guideline also recommended an IP DNase dose of $5 \mathrm{mg}$, prepared in $30 \mathrm{~mL}$ of sterile water. The guideline further recommended a dwell time of 60 minutes and suggested administering these IP agents twice daily for a maximum of 6 total doses. Therefore, the implementation of these guidelines, may have affected the dosing regimens and pharmacy preparation we assessed in the later patients.

Finally, given the retrospective nature of the analysis we were unable to control for other variables that may have affected the efficacy or safety of IP t-PA and IP DNase. It is unknown if any concomitant therapies or any non-pharmacologic strategies affected the results of the study.

\section{Conclusion}

The majority of patients at our institution received concomitant IP t-PA and IP DNase after systemic therapy and chest tube drainage for treatment of pleural infections had been attempted. Administration of IP t-PA and IP DNase demonstrated improved drainage of pleural infections with minimal harm to patients. 


\section{References}

[1] Light, R.W., Girard, W.M., Jenkinson, S.G. and George, R.B. (1980) Parapneumonic Effusions. American Journal of Medicine, 69, 507-512. http://dx.doi.org/10.1016/0002-9343(80)90460-X

[2] Farjah, F., Symons, R.G., Krishnadasan, B., Wood, D.E. and Flum, D.R. (2007) Management of Pleural Space Infections: A Population-Based Analysis. Journal of Thoracic and Cardiovascular Surgery, 133, 346-351. http://dx.doi.org/10.1016/j.jtcvs.2006.09.038

[3] Maslove, D.M., Chen, B.T., Wang, H. and Kuschner, W.G. (2013) The Diagnosis and Management of Pleural Effusions in the ICU. Journal of Intensive Care Medicine, 1, 24-26. http://dx.doi.org/10.1177/0885066611403264

[4] Maskell, N.A., Davies, C.W.H., Nunn, A.J., et al. (2005) U.K. Controlled Trial of Intrapleural Streptokinase for Pleural Infection. New England Journal of Medicine, 352, 865-874. http://dx.doi.org/10.1056/NEJMoa042473

[5] Netten, A., Dennett, J. and Knight, J. (1999) Unit Costs of Health and Social Care. Personal Social Services Research Unit, University of Kent. Canterbury.

[6] Davies, R.J., Traill, Z.C. and Gleeson, F.V. (1997) Randomised Controlled Trial of Intrapleural Streptokinase in Community Acquired Pleural Infection. Thorax, 52, 416-421. http://dx.doi.org/10.1136/thx.52.5.416

[7] Bouros, D., Schiza, S., Tzanakis, N., Chalkiadakis, G., Drositis, J. and Siafakas, N. (1999) Intrapleural Urokinase versus Normal Saline in the Treatment of Complicated Parapneumonic Effusions and Empyema: A Randomized, DoubleBlind Study. American Journal of Respiratory and Critical Care Medicine, 159, 37-42. http://dx.doi.org/10.1164/ajrccm.159.1.9803094

[8] Tokuda, Y., Matsushima, D., Stein, G.H. and Miyagi, S. (2006) Intrapleural Fibrinolytic Agents for Empyema and Complicated Parapneumonic Effusions: A Meta Analysis. Chest, 129, 783-790. http://dx.doi.org/10.1378/chest.129.3.783

[9] Rahman, N.M., Phil, D., Maskell, N.A., et al. (2011) Intrapleural Use of Tissue Plasminogen Activator and DNase in Pleural Infection. New England Journal of Medicine, 365, 518-526. http://dx.doi.org/10.1056/NEJMoa1012740

[10] Skeete, D.A., Rutherford, E.J., Schlidt, S.A., Abrams, J.E., Parker, L.A. and Rich, P.B. (2004) Intrapleural Tissue Plasminogen Activator for Complicated Pleural Effusions. Journal of Trauma, 57, 1178-1183. http://dx.doi.org/10.1097/01.TA.0000141879.67441.52

[11] Diacon, A.H., Theron, J., Schuurmans, M.M., Van de Wal, B.W. and Bolliger, C.T. (2004) Intrapleural Streptokinase for Empyema and Complicated Parapneumonic Effusions. American Journal of Respiratory and Critical Care Medicine, 170, 49-53. http://dx.doi.org/10.1164/rccm.200312-17400C

[12] Tuncozgur, B., Ustunsoy, H., Sivrikoz, M.C., et al. (2001) Intrapleural Urokinase in the Management of Parapneumonic Empyema: A Randomised Controlled Trial. International Journal of Clinical Practice, 55, 658-660.

[13] Simpson, G., Roomes, D. and Reeves, B. (2003) Successful Treatment of Empyema Thoracis with Human Recombinant Deoxyribonuclease. Thorax, 58, 365-366. http://dx.doi.org/10.1136/thorax.58.4.365 
Scientific Research Publishing (SCIRP) is one of the largest Open Access journal publishers. It is currently publishing more than 200 open access, online, peer-reviewed journals covering a wide range of academic disciplines. SCIRP serves the worldwide academic communities and contributes to the progress and application of science with its publication.

Other selected journals from SCIRP are listed as below. Submit your manuscript to us via either submit@scirp.org or Online Submission Portal.
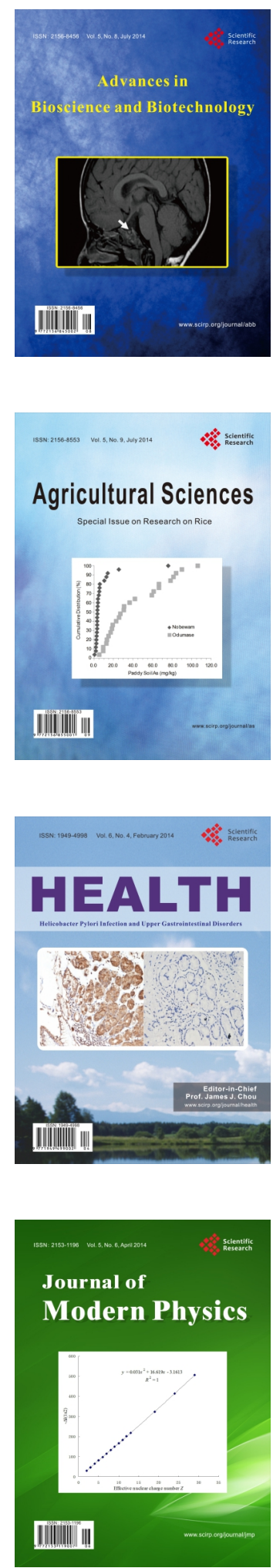
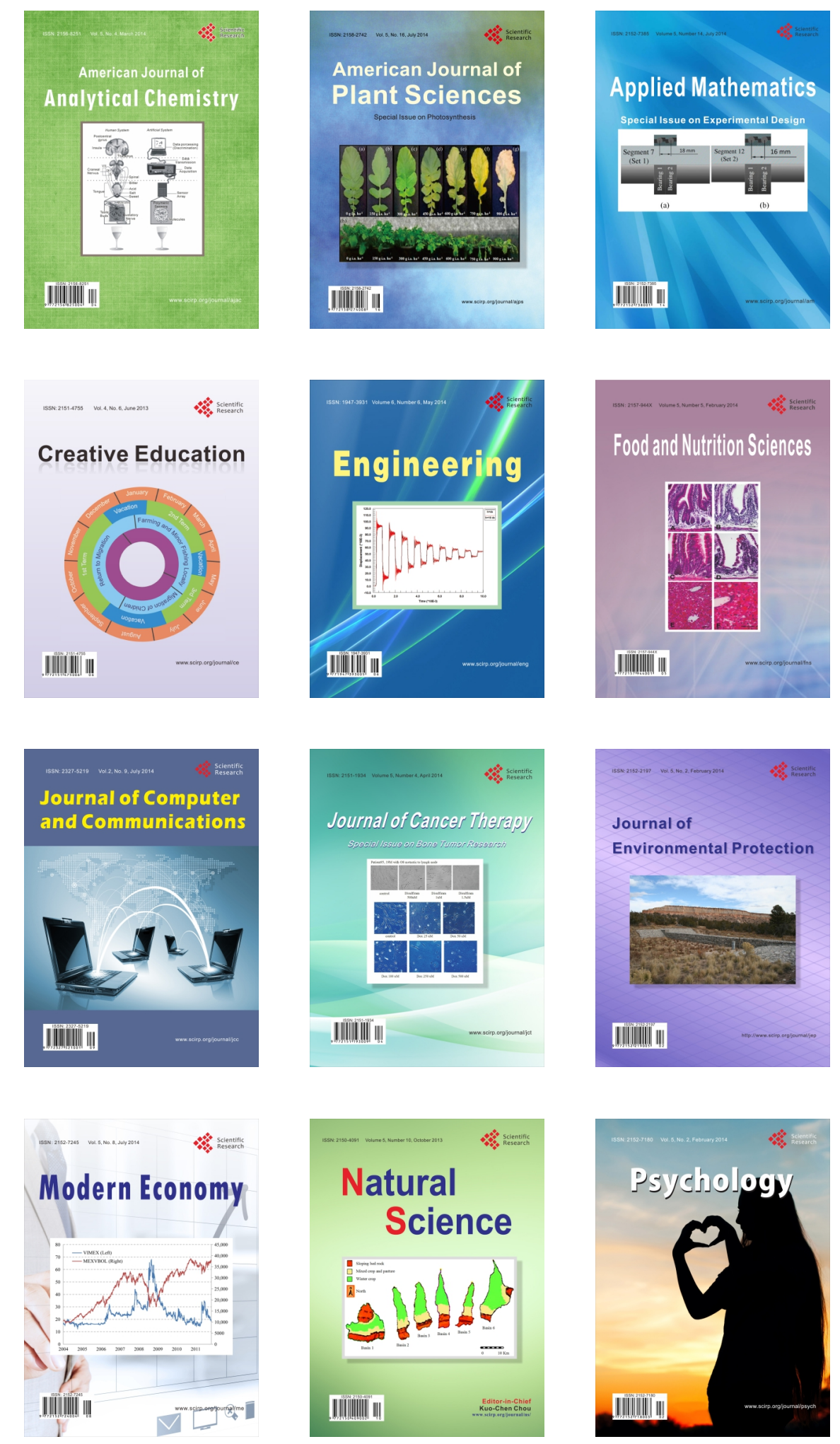